\title{
Fright or Flight? Behavioural Responses of Kangaroos to Drone-Based Monitoring
}

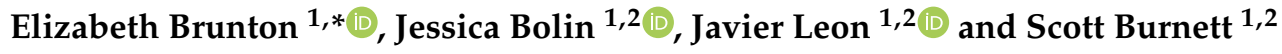 \\ 1 University of the Sunshine Coast, 91 Sippy Downs Drive, Sippy Downs, QLD 4556, Australia; \\ jbolin@usc.edu.au (J.B.); jleon@usc.edu.au (J.L.); sburnett@usc.edu.au (S.B.) \\ 2 Global-Change Ecology Research Group, School of Science and Engineering, University of the Sunshine \\ Coast, Sippy Downs, QLD 4556, Australia \\ * Correspondence: ebrunton@usc.edu.au; Tel.: +61-7-458-214-754
}

Received: 13 March 2019; Accepted: 21 April 2019; Published: 24 April 2019

\begin{abstract}
Drones are often considered an unobtrusive method of monitoring terrestrial wildlife; however research into whether drones disturb wildlife is in its early stages. This research investigated the potential impacts of drone monitoring on a large terrestrial mammal, the eastern grey kangaroo (Macropus giganteus), in urban and peri-urban environments. We assessed the response of kangaroos to drone monitoring by analysing kangaroo behaviour prior to and during drone deployments using a linear modelling approach. We also explored factors that influenced kangaroo responses including drone altitude, site characteristics and kangaroo population dynamics and demographics. We showed that drones elicit a vigilance response, but that kangaroos rarely fled from the drone. However, kangaroos were most likely to flee from a drone flown at an altitude of $30 \mathrm{~m}$. This study suggests that drone altitude is a key consideration for minimising disturbance of large terrestrial mammals and that drone flights at an altitude of 60-100 m above ground level will minimise behavioural impacts. It also highlights the need for more research to assess the level of intrusion and other impacts that drone surveys have on the behaviour of wildlife and the accuracy of the data produced.
\end{abstract}

Keywords: vigilance; behavioural response; anthropogenic disturbance; UAV; UAS; eastern grey kangaroo; wildlife survey

\section{Introduction}

There is growing interest in the use of drones as a tool in wildlife ecology as the technology has become more available and less expensive in recent years [1]. While many are utilising drones to monitor and count [2] terrestrial [3] and marine wildlife, few studies have assessed the impact of this type of monitoring on the behaviour of terrestrial mammals [4]. To date, most studies assessing behavioural responses of wildlife to drones have focused on marine vertebrates [5-8] and birds [9-12].

The type and extent of disturbance from drones reported in these studies has been found to vary with taxa, group size and season $[10,13,14]$. However, the characteristics of the drone and flight scheme adopted influence animal behaviour. A review of disturbance caused by unmanned aircraft systems [14] found that the type of drone and flight pattern used in surveys influenced the strength of the behavioural response of target animals. The altitude at which the drone is flown has also been shown to influence responses of seabirds, but the effect varied between species $[11,15,16]$.

Quantifying animal behavioural responses to this type of survey method is essential to understanding the impacts on both target and nontarget species. There is a need to assess whether drones can cause changes in behaviour and or changes in spatial use, which, in turn, may compromise productivity and viability of study populations [14]. Previous studies have used observations of 
evasive or avoidance behaviour to measure drone disturbance [10-13], as well as using vigilance [15] or changes in movement and spatial use $[9,17]$ as an indicator of disturbance.

This study assesses both avoidance and vigilance behaviour of a large terrestrial mammal, the eastern grey kangaroo (Macropus giganteus), in response to repeated drone surveys under a range of conditions. Eastern grey kangaroos are a gregarious macropod species, which live in groups or 'mobs' that can range between 5 and 70 individuals [18-20]. They are a predominantly sedentary species showing fidelity to their home ranges which vary in size between 20 and 120 ha [19,21-23]. While the popularity of using drones to monitor macropod populations in Australia is growing [24], there has been no research published on their potential impact on kangaroo welfare or the biases that may be introduced to drone-based survey because of fauna behavioural responses.

We hypothesised that both antipredator and overall vigilance by kangaroos would increase as a result of drone presence, and with greater proximity of the drone. Therefore, this study aimed to determine the response of kangaroos and the potential impacts of drone monitoring by assessing: (i) vigilance; (ii) avoidance behaviour; and (iii) environmental and logistical factors that may influence kangaroo behavioural responses to drones.

\section{Materials and Methods}

\subsection{Study Site}

This study was conducted in two separate locations on the sub-tropical Sunshine Coast in Queensland, Australia. The first site (Sippy Downs) $\left(26^{\circ} 43^{\prime} 01^{\prime \prime} \mathrm{S}, 153^{\circ} 03^{\prime} 56^{\prime \prime}\right.$ E) was an urban site located on a university campus where kangaroos persist in the urban matrix amongst built infrastructure, preferentially utilising grass and forest areas on the campus. Pressures from ongoing infrastructure development, human population growth and urban encroachment on kangaroo habitats have caused a steep decline in this kangaroo population from approximately 80 kangaroos in 2010 [25] to 15 resident kangaroos remaining on site at the time of this study (average mob size was 3.4). The second site (Lake Weyba) $\left(26^{\circ} 26^{\prime} 16^{\prime \prime} \mathrm{S}, 153^{\circ} 03^{\prime} 44^{\prime \prime}\right.$ E) was a peri-urban private property dominated by coastal heath, with small patches of mowed lawns throughout. The site, which is a gazetted nature refuge with only low-rise guesthouses, supports a resident mob size of between 25 and 30 kangaroos (average mob size of 10.9). Kangaroos at both sites were habituated to some level of human presence and disturbance; however, to our knowledge, kangaroos had no prior exposure to drones being flown overhead.

\subsection{Drone Deployments}

We assessed the response of kangaroos to drone monitoring by quantifying eastern grey kangaroo behaviour and vigilance both immediately prior to and during drone deployments. Drone deployments were conducted between May and October 2017 between the hours of 0600 and 1700. In total, we conducted 38 drone deployments across both sites, with 85 instances of drones flying over kangaroos. A single quadcopter (UAV DJI Phantom 3 Advanced) was used with a video and IR camera attached. The drone has a range of $\sim 1 \mathrm{~km}$ and a maximum ascent speed of $5 \mathrm{~m} / \mathrm{s}$ and maximum speed of $16 \mathrm{~m} / \mathrm{s}$. At hovering height of $1 \mathrm{~m}$, the noise at ground level is up to $90 \mathrm{dBA}$ (baseline/drone off noise of $38 \mathrm{dBA}$ ). At a height of $30 \mathrm{~m}$ the noise level is $54.5 \mathrm{dBA}$ and at $60 \mathrm{~m} 49.5 \mathrm{dBA}$. For comparison, a smaller drone such as a DJI Mavic Pro has a noise level of $45.5 \mathrm{dBA}$ at $30 \mathrm{~m}$ (baseline of $43 \mathrm{dBA}$ ), and a larger drone, such as a DJI Inspire 2, has a noise level of $55.5 \mathrm{dBA}$ at $30 \mathrm{~m}$ (baseline of $41 \mathrm{dBA}$ ).

Prior to each drone deployment, sites were searched on foot with the aid of binoculars to locate kangaroos. Once kangaroos were located and two on-ground observers were in place, the drone was launched. During each focal period all observers and ancillary researchers, remained stationary in order to minimise additional disturbance to kangaroos. Drone take-off occurred an average $40 \mathrm{~m}$ distance away from the kangaroos at the Sippy Downs site, and an average $80 \mathrm{~m}$ distance at Lake Weyba. Upon starting, the drone ascended to $120 \mathrm{~m}$ altitude before taking a horizontal flight path 
over the target kangaroos and multiple kangaroos were assessed each flight. The drone was flown in repeated transect lines at decreasing altitudes of $120 \mathrm{~m}, 100 \mathrm{~m}, 60 \mathrm{~m}$ and $30 \mathrm{~m}$ above the target kangaroos. Each flight lasted between 6 and $7 \mathrm{~min}$ and encompassed each altitude. On most days, we undertook multiple deployments at different times of day over the same kangaroos. An average of 2 deployment replicates per day were undertaken $(\max =5)$, with a minimum of $1 \mathrm{~h}$ between each deployment on any one day. Deployment days occurred an average of 15 days apart with always at least one day between deployments. Observers noted distinctive physical characteristics of each target kangaroo, e.g., size, scars, facial features and monitored their movements between drone deployments in order to identify individual kangaroos. This was possible due to the low numbers of kangaroos and/or limited area over which they occurred during the focal period. Where kangaroos could be identified by observer recognition, the number of drone deployments over each kangaroo per day was recorded as a daily deployment replicate in order to assess the impact of multiple flights in one day.

\subsection{Kangaroo Behaviour}

Kangaroos were observed through binoculars from a distance of 50-100 $\mathrm{m}$ prior to and during each drone deployment. We recorded behaviour in the field and also collected data for use in later video analyses. Video footage (Samsung 42MP Schneider) of the target individuals was recorded both before and during drone deployment. Observers used a handheld laser rangefinder (Bushnell) to record the distance from observer of each kangaroo. For each kangaroo/drone interaction we recorded (i) behaviour at first sighting, i.e., before focal period (resting, foraging or vigilant); (ii) distance to observer; (iii) mob size; and (iv) sex. Due to the urban nature of the sites, other sources of anthropogenic disturbance were often present including pedestrians and vehicles. Where possible, we did not deploy the drone when these types of disturbance were in close proximity to kangaroos. If the kangaroos were seen to be disturbed by other factors during drone deployment, the data were excluded from the analyses. Kangaroo behaviour was categorised on the basis of an ethogram (Table 1) which we developed based on methods used by Favreau et al. [26]. Vigilance behaviour was defined as a response to disturbance where the individual kangaroo's head was raised above its horizontal plane when standing or upright and looking in one direction $[27,28]$.

Table 1. Ethogram used for behavioural classification.

\begin{tabular}{|c|c|c|c|c|}
\hline $\begin{array}{l}\text { Type of } \\
\text { Behaviour }\end{array}$ & Behaviour & Code & Type & Description of Behaviour \\
\hline \multirow[t]{4}{*}{ Vigilance } & Antipredator & PC & Event & $\begin{array}{l}\text { Focal animal is alert, head raised above } \\
\text { horizontal plane when standing or upright, } \\
\text { with head facing perceived threat }\end{array}$ \\
\hline & Social & SC & Event & $\begin{array}{l}\text { Focal animal is alert, head raised above } \\
\text { horizontal plane when standing or upright, } \\
\text { with head facing other members of mob }\end{array}$ \\
\hline & Flee $(<10 \mathrm{~m})$ & FL & Event & $\begin{array}{l}\text { Focal animals flee from original position to } \\
\text { a position less than } 10 \mathrm{~m} \text { away. }\end{array}$ \\
\hline & Flee $(>10 \mathrm{~m})$ & FL & Event & $\begin{array}{l}\text { Focal animals flee from original position to } \\
\text { a position more than } 10 \mathrm{~m} \text { away. }\end{array}$ \\
\hline Food-Related & Forage & $\mathbf{F}$ & State & $\begin{array}{l}\text { Focal animal is consuming food in its } \\
\text { environment }\end{array}$ \\
\hline Solitary & Rest & $\mathbf{R}$ & State & $\begin{array}{l}\text { Focal animal is laying down and stays in } \\
\text { one place }\end{array}$ \\
\hline Other & Out of sight & OOS & State & Focal animal is out of sight \\
\hline
\end{tabular}

\subsubsection{Field Observations}

For each kangaroo we recorded if it fled or not in response to the drone. If kangaroos fled during drone deployment we recorded the altitude of the drone at that point in time. At the completion of 
each drone deployment, we categorised each kangaroos overall behavioural response to the drone as (i) no vigilance, (ii) vigilance (if any vigilant behaviour occurred), (iii) flee less than ten metres and (iv) flee more than ten metres.

\subsubsection{Video Analyses}

Video footage suitable for vigilance analysis was available for 25 of the drone flights and we assessed the response of kangaroos in 76 instances. Kangaroos were filmed for the entirety of each drone deployment. However, as drone deployment times were variable due to site and weather conditions, only the first five minutes of video footage were analysed for each pre-drone deployment and drone deployment period. Analyses were based on a comparison between individual kangaroo behaviour during the five minutes prior to launching the drone and the first five minutes after the drone was launched and deployed overhead. During video analysis, a focal sampling method was used, where one individual was observed for the entire video and all behavioural instances were recorded. For each target kangaroo, we documented the frequency of vigilant acts and the total time spent in vigilance for both pre-drone deployment and drone deployment periods. We further classified vigilance behaviour at three levels: social, antipredator and total (social + antipredator) [26] (Table 1). Antipredator vigilance occurs when an animal pays full attention to a perceived predator whereas social vigilance involves interacting with and gaining information about group members [29,30]. If a kangaroo took flight from the area during drone deployment, this was classified as fleeing the area, and the kangaroo was classified as out of sight for the remainder of the focal period.

\subsection{Statistical Analyses}

We explored the reactions of kangaroos to drone surveillance in several different ways. All analyses were carried out in the R environment [31]. We analysed kangaroo behaviour data from field observations and video analyses.

\subsubsection{Field Observations}

We assessed whether kangaroos fled more often during drone deployment using a binomial test to determine if the presence of the drone influenced whether kangaroos fled during drone flights.

To investigate the influence of each drone altitude on kangaroo flight we built a GLM with frequency with which kangaroos fled the drone as the response variable.

To assess how kangaroos were likely to respond to drone presence, we constructed a Poisson generalised linear model (GLM) to compare the counts of overall behavioural responses (none, vigilance, flight $>10 \mathrm{~m}$ and full flight) to drone presence.

\subsubsection{Video Analyses}

To test whether the binary response variable (i.e., flee or not flee) was predicted by site, distance to observer, sex, daily deployment replicate, behaviour at first sight and mob size and a generalised linear mixed effects model (GLMM) by maximum likelihood was built using the "lme4" package [32]. The model included drone deployment ID as a random effect and an interaction between mob size and site. All continuous variables were standardised prior to model selection in order to ensure comparability of coefficients. Maximal models were built and model selection used a stepwise backward procedure with insignificant predictors removed based on changes in AICs (Akaike Information Criterion) and log-likelihood ratio tests [33]. Note that for simplicity, only final models are shown (Table 2). Our final models contain only predictors that caused fit to deteriorate significantly when they were removed from the model. 
Table 2. Parameter estimates, for generalized linear models fitted for (a) frequency of times kangaroos fled during drone deployment as a function of drone altitude and (b) frequency of behavioural responses to drone deployment. Significant predictors are indicated with *.

\begin{tabular}{|c|c|c|c|c|}
\hline Coefficient & Estimate & Standard Error & $\mathbf{Z}$ & $p$-Value \\
\hline \multicolumn{5}{|c|}{ (a) Frequency Fled $\sim$ Drone Altitude } \\
\hline Intercept & 2.773 & 0.25 & 11.09 & $<0.001$ \\
\hline Drone altitude $60 \mathrm{~m}$ & -2.079 & 0.75 & -2.773 & $0.005 *$ \\
\hline Drone altitude $100 \mathrm{~m}$ & -1.386 & 0.559 & -2.48 & $0.013 *$ \\
\hline Drone altitude $120 \mathrm{~m}$ & -1.386 & 0.559 & -2.48 & $0.013 *$ \\
\hline \multicolumn{5}{|c|}{ (b) Frequency of Act $\sim$ Behavioural Response to Drone } \\
\hline Intercept & 2.8904 & 0.2357 & 12.263 & $<0.001$ \\
\hline Flight & -0.4925 & 0.3827 & -1.287 & 0.198 \\
\hline Full Flight & 0.0 .0000 & 0.3333 & 0.000 & 1.000 \\
\hline Vigilance & 1.5404 & 0.2597 & 5.931 & $<0.001 *$ \\
\hline
\end{tabular}

We built three models (GLMMs) to explore the predictive power of the fixed predictors: drone deployment (present or absent); site; mob size; daily deployment replicate; sex; and distance to observer on (1) total number of vigilant acts (Poisson), (2) total time spent vigilant (sec) (Gaussian) and (3) time spent in antipredator vigilance (sec) (Gaussian). Drone deployment ID was included as a random effect in these models and all continuous variables were standardised prior to model selection. Model simplification followed the same stepwise backward procedure outlined above (Table 3). We also conducted a paired T-test to compare: the amount of time overall that kangaroos spent in social versus antipredator vigilance during drone deployment.

Table 3. Parameter estimates from generalised linear mixed-effects models quantifying the behavioural responses of eastern grey kangaroos to drone deployment. Only models are shown, and significant predictors are indicated with *.

\begin{tabular}{lcccc}
\hline & Estimate & Standard Error & $\mathbf{Z} /(\mathbf{t})$ & $p$-Value \\
\hline (a) Fled from Drone $\sim$ Daily Deployment & Replicate + Behaviour & at First Sight & & \\
Intercept & -1.9979 & 0.6864 & -2.911 & $0.004^{*}$ \\
Daily deployment replicate & 0.9338 & 0.2522 & 3.703 & $<0.001^{*}$ \\
Behaviour at first sight (foraging) & 0.2708 & 0.7287 & -0.372 & 0.710 \\
Behaviour at first sight (vigilant) & 2.5151 & 1.0091 & 2.869 & $0.013^{*}$ \\
\hline (b) Number of vigilant acts $\sim$ Mob size + Site & & & \\
Intercept & 0.495 & 0.1184 & 4.183 & $<0.001^{*}$ \\
Mob size & -0.413 & 0.1179 & -3.512 & $<0.001^{*}$ \\
Site (Peri-urban) & 0.403 & 0.2223 & 1.813 & 0.069 \\
\hline (c) Total Time Spent Vigilant $\sim$ Drone Deployment + Distance to Observer & & \\
Intercept & 47.408 & 6.846 & $(6.925)$ & $<0.001^{*}$ \\
Drone Deployment (present) & 17.434 & 7.133 & $(2.444)$ & $0.016^{*}$ \\
Distance to Observer & -12.359 & 5.863 & $(-2.108)$ & $0.0384^{*}$ \\
\hline (d) Antipredator Vigilance Time $\sim$ Drone Deployment + Distance to Observer & & \\
Intercept & 77.6 & 17.2079 & $(4.510)$ & $<0.001 *$ \\
Drone Deployment & 14.5526 & 7.4033 & $(1.966)$ & 0.0530 \\
Distance to Observer & -0.5737 & 0.2523 & -2.274 & $0.0259 *$ \\
\hline
\end{tabular}

\subsection{Ethics and Permits}

This research was conducted under University of the Sunshine Coast Animal Ethics permit ANA1489. The drone pilot (JL) held a CASA Remote Pilot License (RePL) and notified CASA about flights via the online portal. 


\section{Results}

\subsection{Field Observations}

The most common behavioural response of kangaroos to drone deployment was vigilance $(p<0.001, \mathrm{n}=132$, Table 2b, Figure 1a). Of the 132 observations of kangaroos during drone deployments, kangaroos fled the site on $21 \%$ of occasions and a binomial test revealed that kangaroos were equally likely to flee when the drone was not flown $(n=28)$. However, the altitude of the drone was a significant predictor of kangaroos fleeing (Table 2a). When kangaroos did flee, they fled more often when the drone was flown at $30 \mathrm{~m}$ altitude compared to the other heights tested (Figure 1b).

(a)

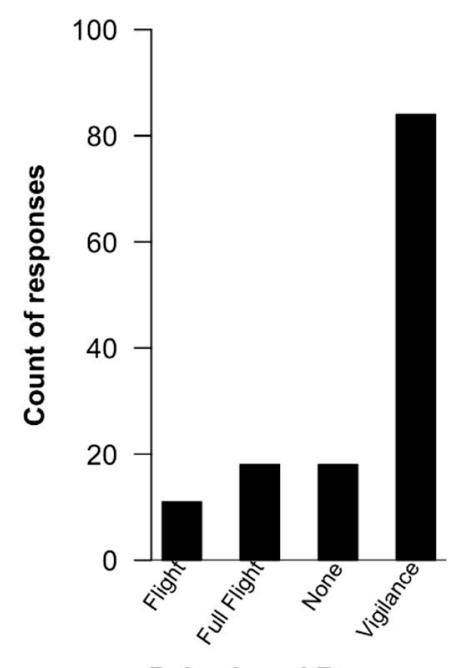

Behavioural Response (b)

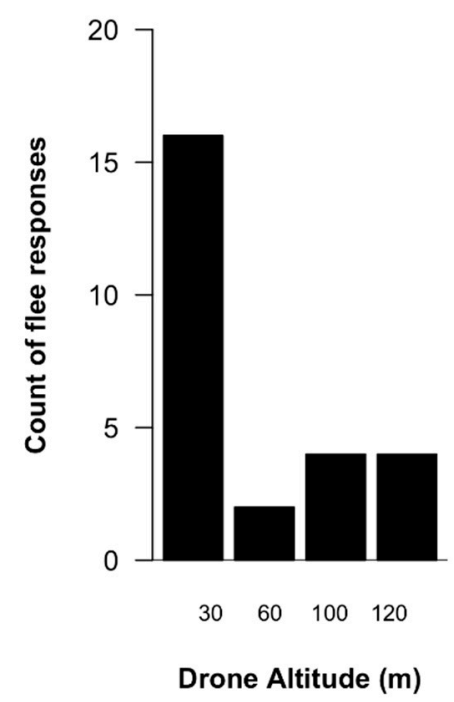

Figure 1. (a) Frequencies of eastern grey kangaroo behavioural responses to drone deployment. Flight is defined as when the focal kangaroo flees less than $10 \mathrm{~m}$, whereas full flight is when the focal kangaroo flees the area. (b) Frequencies of eastern grey kangaroo flight in response to drone altitude.

\subsection{Video Analyses}

Kangaroos were more likely to flee with increasing number of drone deployments per day $(\mathrm{n}=76$, $p<0.001$, Table 3a) and if they were vigilant on first sighting prior to the launch of the drone $(p=0.013$, Table $3 a)$. However, mob size and site were better predictors of the number of vigilant acts than drone deployment (Table 3b). The number of vigilant acts was negatively correlated with mob size $(\mathrm{t}=-3.512, p<0.001$, Table $3 \mathrm{~b})$, and kangaroos at the peri-urban site exhibited more vigilant acts, compared to the urban site $(t=1.813 p, p=0.069$, Table $3 b)$. Drone presence was a significant predictor of total time spent vigilant $(t=2.444, p=0.016$, Table $3 c$, Figure $2 a)$. Furthermore, drone deployment and distance to observer were both significant predictors of time spent in antipredator vigilance, with closer observers to the kangaroos correlating with longer periods of antipredator vigilance $(p=0.0259$, Table 3d, Figure 2b). Overall, when vigilant, kangaroos spent an average of $41.82 \mathrm{sec}(95 \% \mathrm{CI}=$ 31.01-52.62 sec) more time in antipredator vigilance, compared to social vigilance $(\mathrm{t}=7.64, p<0.001)$. 
(a)

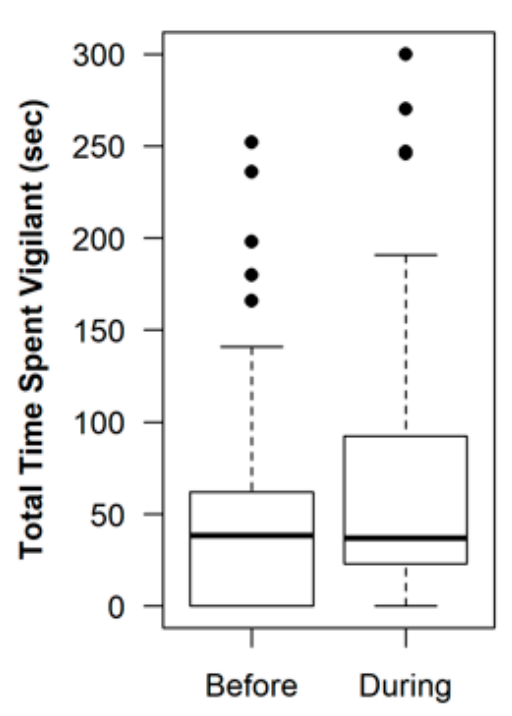

Drone Deployment

\section{(b)}

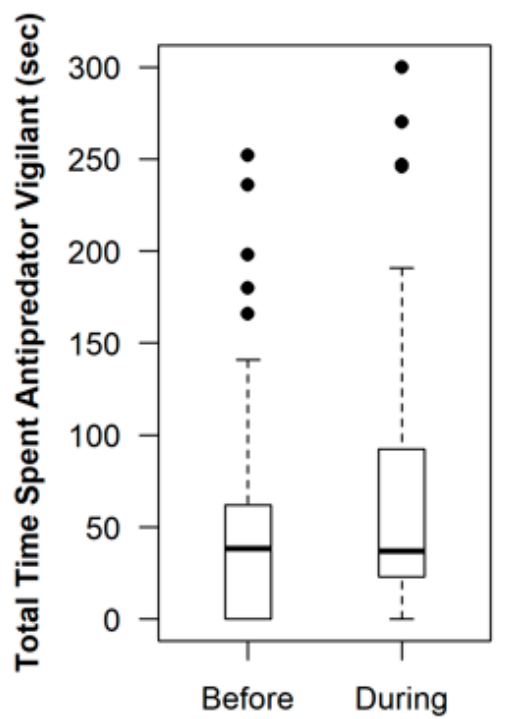

Drone Deployment

Figure 2. Eastern grey kangaroos spent more time on average in (a) total vigilance and (b) antipredator vigilance during drone deployments, compared to before drone deployments.

\section{Discussion}

The kangaroo behaviour observed in this study suggests that kangaroos are unlikely to flee when a drone is flown overhead at an altitude higher than $30 \mathrm{~m}$ and that drone-based aerial monitoring is unlikely to significantly change kangaroo movements. However, we demonstrated that, for urban and peri-urban kangaroo populations, the most common response to a drone is increased vigilance and we showed that the presence of a drone elicited an increase in time spent in vigilance. Both overall and antipredator vigilance increased when the drone was present, suggesting that drone monitoring does have the potential to disturb and stress kangaroos. It is unclear whether the animals were disturbed by the unfamiliar noise of the drone or the presence of an aerial object that may be perceived as a predator, as kangaroo joeys are not only predated on by dingoes (Canis lupus dingo), wild dogs (Canis familiaris) and foxes (Vulpes vulpes), but also by wedge-tailed eagles (Aquila audax) [34].

The exact impact of drone monitoring on kangaroo behaviour is difficult to ascertain however, our findings demonstrate at least a short-term impact. Ongoing or repeated exposure to stressors leading to increased vigilance can lead to a reduction in animal fitness, with less time invested in foraging and caring for young [35]. Food intake is reduced as a result of increased vigilance and, as antipredator vigilance was more common than social vigilance, in our study kangaroos invested less time in foraging and providing care for young during drone deployments. Increases in vigilant behaviour of kangaroos undergoing infrequent monitoring are likely to have only minimal short-term impacts on kangaroo fitness. However, changes in vigilance behaviour may become more important to the fitness of terrestrial mammals at times of environmental stress or in significant breeding periods. As drones have also been utilised to study threatened species such as rhinoceroses [36], chimpanzees (Pan troglodytes) [37] and orangutans (Pongo abelii) [38], even small detrimental impacts on breeding or fitness of endangered animals would be of concern.

There were also differences in the behavioural response of kangaroos between the study sites and this may be due to the site characteristics. Animals in environments differing in level of urbanisation often show differences in behaviour and those in urban environments may be less influenced by anthropogenic noise as a result of habituation [39]. An effect of habituation of the kangaroos to daily noise, disturbance and exposure to humans in the urban site may explain the lower level response 
elicited by drone deployment at the urban site than the peri-urban. Whilst the peri-urban site had a daily presence of humans, the number of people and/or vehicles present on site at any time was low. This is in comparison to the urban site that had hundreds of people and vehicles present on most days. It is possible that the level of urbanisation and exposure to noise may have habituated those urban kangaroos to anthropogenic disturbance with the effect of no change in the number of vigilance acts in response to the drone. However, given that drones may be a novel source of anthropogenic disturbance, they are also likely to be perceived differently to other daily sources of disturbance on these sites. It may be simply that the greater background noise at the urban site made the drone less perceptible to kangaroos.

It is important to note that it is beyond the scope of this study to understand what site-specific factors may lead to intersite variations in kangaroo response to drones. These variations in behavioural response in sites with different levels of urbanisation do, however, highlight that while we have shown that this method of monitoring has minimal impact in the sites that we tested, it cannot be assumed that kangaroos in all ecological contexts will behave in the same way as our study animals. This has implications for surveying both kangaroos and other large mammals in sites with different disturbance histories. Both the intensity of behavioural responses to drone disturbance and the implications of these responses on animal wellbeing require further research in order to ascertain the extent to which drone monitoring influences data collected.

Drone deployment protocols also influence the impact of drone monitoring. We show here that drones flown at an altitude of $30 \mathrm{~m}$ are more likely to cause a kangaroo to flee than are those flown at higher altitudes. Obviously, at lower altitudes the drone is more likely to be heard and seen by the kangaroos and perceived as a potential threat. This result is supported by other studies where drones flown at altitudes of less than $40 \mathrm{~m}$ induced evasive behaviour on African herbivore species [4] crocodiles (Crocodylus porosus) [13] and bird species [9-11,13]. Repeated drone monitoring of kangaroos may create a lasting stress response in target animals and reduce the reliability of any ecological interpretations. In our study, kangaroos showed an increased likelihood of flight from the drone with an increasing number of drone deployments per day; this suggests that they did not become habituated to the presence of the drone. Many studies on birds have also indicated an absence of short-term habituation to drones after multiple flights $[12,15,40]$.

No direct comparisons have been made comparing the behavioural impacts of on-foot surveys and drone surveys of large mammals and this is a key area for future research. However, there is evidence that approaching kangaroos on both on foot and in vehicles leads to fleeing behaviour in kangaroos, and kangaroos approached on foot showed higher rates of evasive behaviour than when approached in a vehicle [41]. In this study, both types of approaches did lead to some flight in kangaroos. If drones are flown at an altitude that limits or stops any effects on movement behaviour of target animals, they have the potential to provide a superior method of monitoring. It should also be acknowledged however that changes in movement of target animals should not be the only consideration when assessing disturbance. While our research demonstrates that kangaroos change their behaviour in response to drone monitoring it does not assess the full extent and short- and long-term implications of disturbance. In a study on black bears (Ursus americanus), Ditmer et al. [17] recorded a limited behavioural response to drones, although the bears experienced elevated heart rates as a response to drone flights. A study assessing drone disturbance in seabirds also recorded increases in heart rate in response to drones but again behavioural changes were not always observed [11]. It would be useful when conducting drone research if researchers assessed metabolic and physiological responses along with behavioural responses of target species, as this would improve our understanding of this form of wildlife monitoring and the potential implications for wildlife health.

\section{Conclusions}

Our research provides insights into the behavioural responses of a large mammal species to drone surveys. Due to potential implications on animal behaviour, our results suggest that drones should be 
flown at a minimum altitude of $60 \mathrm{~m}$ above target animals. If used in this way, and after preliminary evaluation of potential behavioural effects on the target species, drones may present a superior method of wildlife monitoring compared to often disruptive and invasive on-ground counts. We suggest that drones can be an effective monitoring tool for large terrestrial mammals. Further research on behavioural responses of other species will allow for refinement of drone survey flight protocols to limit unwanted impacts on wildlife and ensure the reliability of information collected.

Author Contributions: Conceptualization, E.B., J.L. and S.B.; Methodology, E.B., J.L. and S.B.; Validation, E.B.; Formal Analysis, E.B. and J.B.; Investigation, E.B., J.B. and J.L.; Resources, J.B. and E.B.; Data Curation, E.B., and J.B.; Writing-Original Draft Preparation, E.B.; Writing-Review \& Editing, E.B., J.B., J.L. and S.B.; Visualization, J.B.; Project Administration, E.B.; Funding Acquisition, E.B., J.L. and S.B.

Funding: This research was funded by Sunshine Coast Council, USC SCC Collaborative grant \#2016-03.

Acknowledgments: The authors thank Richard Burns for assistance with editing and volunteers for their assistance with field work. Peter Nagle and Jacqueline Nolen from Sunshine Coast Council and Anita Brake helped with access to field sites. We thank anonymous reviewers for their help with improving this manuscript.

Conflicts of Interest: The authors declare no conflicts of interest.

\section{References}

1. Linchant, J.; Lisein, J.; Semeki, J.; Lejeune, P.; Vermeulen, C. Are unmanned aircraft systems (UASs) the future of wildlife monitoring? A review of accomplishments and challenges. Mammal Rev. 2015, 45, $239-252$. [CrossRef]

2. Hodgson, J.C.; Mott, R.; Baylis, S.M.; Pham, T.T.; Wotherspoon, S.; Kilpatrick, A.D.; Raja, S.R.; Reid, I.; Terauds, A.; Koh, L.P. Drones count wildlife more accurately and precisely than humans. Methods Ecol. Evol. 2018, 9, 1160-1167. [CrossRef]

3. Mustafa, O.; Barbosa, A.; Krause, D.J.; Peter, H.U.; Vieira, G.; Rümmler, M.-C. State of knowledge: Antarctic wildlife response to unmanned aerial systems. Pol. Biol. 2018, 41, 2377. [CrossRef]

4. Bennitt, E.; Bartlam-Brooks, H.L.A.; Hubel, T.Y.; Wilson, A.M. Terrestrial mammalian wildlife responses to unmanned aerial systems approaches. Sci. Rep. 2019, 9, 2142. [CrossRef] [PubMed]

5. Johnston, D.W. Unoccupied Aircraft Systems in Marine Science and Conservation. Ann. Rev. Mar. Sci. 2019, 11, 439-463. [CrossRef] [PubMed]

6. Torres, L.G.; Nieukirk, S.L.; Lemos, L.; Chandler, T.E. Drone Up! Quantifying Whale Behavior From a New Perspective Improves Observational Capacity. Front. Mar. Sci. 2018, 5. [CrossRef]

7. Hodgson, A.; Kelly, N.; Peel, D. Unmanned Aerial Vehicles (UAVs) for Surveying Marine Fauna: A Dugong Case Study. PLoS ONE 2013, 8, e79556. [CrossRef]

8. Burnett, J.D.; Lemos, L.; Barlow, D.; Wing, M.G.; Chandler, T.; Torres, L.G. Estimating morphometric attributes of baleen whales with photogrammetry from small UASs: A case study with blue and gray whales. Mar. Mammal Sci. 2019, 35, 108-139. [CrossRef]

9. McEvoy, J.F.; Hall, G.P.; McDonald, P.G. Evaluation of unmanned aerial vehicle shape, flight path and camera type for waterfowl surveys: Disturbance effects and species recognition. PeerJ 2016, 4, e1831. [CrossRef]

10. Lyons, M.; Brandis, K.; Callaghan, C.; McCann, J.; Mills, C.; Ryall, S.; Kingsford, R. Bird interactions with drones, from individuals to large colonies. bioRxiv 2017, 109926. [CrossRef]

11. Weimerskirch, H.; Prudor, A.; Schull, Q. Flights of drones over sub-Antarctic seabirds show species- and status-specific behavioural and physiological responses. Pol. Biol. 2018, 41, 259-266. [CrossRef]

12. Vas, E.; Lescroël, A.; Duriez, O.; Boguszewski, G.; Grémillet, D. Approaching birds with drones: first experiments and ethical guidelines. Biol. Lett. 2015, 11. [CrossRef]

13. Bevan, E.; Whiting, S.; Tucker, T.; Guinea, M.; Raith, A.; Douglas, R. Measuring behaviorral responses of sea turtles, saltwater crocodiles, and crested terns to drone disturbance to define ethical operating thresholds. PLoS ONE 2018, 13, e0194460. [CrossRef]

14. Mulero-Pázmány, M.; Jenni-Eiermann, S.; Strebel, N.; Sattler, T.; Negro, J.J.; Tablado, Z. Unmanned aircraft systems as a new source of disturbance for wildlife: A systematic review. PLoS ONE 2017, 12, e0178448. [CrossRef] 
15. Rümmler, M.-C.; Mustafa, O.; Maercker, J.; Peter, H.-U.; Esefeld, J. Measuring the influence of unmanned aerial vehicles on Adélie penguins. Pol. Biol. 2016, 39, 1329-1334. [CrossRef]

16. Christiansen, F.; Rojano-Doñate, L.; Madsen, P.T.; Bejder, L. Noise Levels of Multi-Rotor Unmanned Aerial Vehicles with Implications for Potential Underwater Impacts on Marine Mammals. Front. Mar. Sci. 2016, 3. [CrossRef]

17. Ditmer, M.A.; Vincent, J.B.; Werden, L.K.; Tanner, J.C.; Laske, T.G.; Iaizzo, P.A.; Garshelis, D.L.; Fieberg, J.R. Bears Show a Physiological but Limited Behavioral Response to Unmanned Aerial Vehicles. Curr. Biol. 2015, 25, 2278-2283. [CrossRef]

18. Taylor, R.J. Group size in the eastern grey kangaroo, Macropus giganteus, and the wallaroo, Macropus robustus. Wildl. Res. 1982, 9, 229-237. [CrossRef]

19. Moore, B.D.; Coulson, G.; Way, S. Habitat selection by adult female eastern grey kangaroos. Wildl. Res. 2002, 29, 439-445. [CrossRef]

20. Best, E.C.; Seddon, J.M.; Dwyer, R.G.; Goldizen, A.W. Social preference influences female community structure in a population of wild eastern grey kangaroos. Anim. Behav. 2013, 86, 1031-1040. [CrossRef]

21. Kaufmann, J.H. Field observations of the social behaviour of the eastern grey kangaroo, Macropus giganteus. Anim. Behav. 1975, 23 Pt 1, 214-221. [CrossRef]

22. Jaremovic, R.V.; Croft, D.B. Social-organization of the eastern gray kangaroo (Macropodidae, marsupialia) in southeastern New-south-wales. 1. Groups and group home ranges. Mammalia 1991, 55, 169-185. [CrossRef]

23. Jaremovic, R.V.; Croft, D.B. Comparison of Techniques to Determine Eastern Grey Kangaroo Home Range. J. Wildl. Manag. 1987, 51, 921-930. [CrossRef]

24. Gentle, M.; Finch, N.; Speed, J.; Pople, A. A comparison of unmanned aerial vehicles (drones) and manned helicopters for monitoring macropod populations. Wildl. Res. 2018, 45, 586-594. [CrossRef]

25. Brunton, E.A.; Srivastava, S.K.; Burnett, S. Spatial ecology of an urban eastern grey kangaroo (Macropus giganteus) population: Local decline driven by kangaroo-vehicle collisions. Wildl. Res. 2018, 45, 685-695. [CrossRef]

26. Favreau, F.-R.; Goldizen, A.W.; Pays, O. Interactions among social monitoring, anti-predator vigilance and group size in eastern grey kangaroos. Proc. R. Soc. B Biol. Sci. 2010, 277, 2089-2095. [CrossRef]

27. Jarman, P.J. Group size and activity in eastern grey kangaroos. Anim. Behav. 1987, 35, 1044-1050. [CrossRef]

28. Pays, O.; Jarman, P.J.; Loisel, P.; Gerard, J.-F. Coordination, independence or synchronization of individual vigilance in the eastern grey kangaroo? Anim. Behav. 2007, 73, 595-604. [CrossRef]

29. Elgar, M.A. Predator vigilance and group size in mammals and birds: A critical review of the empirical evidence. Biol. Rev. 1989, 64, 13-33. [CrossRef]

30. Carter, A.J.; Pays, O.; Goldizen, A.W. Individual variation in the relationship between vigilance and group size in eastern grey kangaroos. Behav. Ecol. Sociobiol. 2009, 64, 237-245. [CrossRef]

31. R Core Team. R: A Language and Environment for Statistical Computing; R foundation for Statistical Computing: Vienna, Austria, 2017.

32. Bates, D.; Machler, M.; Bolker, B.M.; Walker, S.C. lme4: Linear Mixed-Effects Models Using Eigen and S4. R Package. 2014. Available online: https://cran.r-project.org/web/packages/lme4/lme4.pdf (accessed on 31 January 2017).

33. Bolker, B.M.; Brooks, M.E.; Clark, C.J.; Geange, S.W.; Poulsen, J.R.; Stevens, M.H.; White, J.S. Generalized linear mixed models: A practical guide for ecology and evolution. Trends Ecol. Evol. 2009, 24, 127-135. [CrossRef]

34. Banks, P.B. Predation-sensitive grouping and habitat use by eastern grey kangaroos: A field experiment. Anim. Behav. 2001, 61, 1013-1021. [CrossRef]

35. Favreau, F.R.; Pays, O.; Fritz, H.; Goulard, M.; Best, E.C.; Goldizen, A.W. Predators, food and social context shape the types of vigilance exhibited by kangaroos. Anim. Behav. 2015, 99, 109-121. [CrossRef]

36. Mulero-Pázmány, M.; Stolper, R.; van Essen, L.D.; Negro, J.J.; Sassen, T. Remotely Piloted Aircraft Systems as a Rhinoceros Anti-Poaching Tool in Africa. PLoS ONE 2014, 9, e83873. [CrossRef]

37. Bonnin, N.; Van Andel, A.C.; Kerby, J.T.; Piel, A.K.; Pintea, L.; Wich, S.A. Assessment of Chimpanzee Nest Detectability in Drone-Acquired Images. Drones 2018, 2, 17. [CrossRef]

38. Wich, S.; Dellatore, D.; Houghton, M.; Ardi, R.; Koh, L.P. A preliminary assessment of using conservation drones for Sumatran orang-utan (Pongo abelii) distribution and density. J. Unmanned Veh. Syst. 2015, 4, 45-52. [CrossRef] 
39. Birnie-Gauvin, K.; Peiman, K.S.; Gallagher, A.J.; de Bruijn, R.; Cooke, S.J. Sublethal consequences of urban life for wild vertebrates. Environ. Rev. 2016, 24, 416-425. [CrossRef]

40. Goebel, M.E.; Perryman, W.L.; Hinke, J.T.; Krause, D.J.; Hann, N.A.; Gardner, S.; LeRoi, D.J. A small unmanned aerial system for estimating abundance and size of Antarctic predators. Pol. Biol. 2015, 38, 619-630. [CrossRef]

41. Wolf, I.D.; Croft, D.B. Minimizing disturbance to wildlife by tourists approaching on foot or in a car: A case study of kangaroos in the Australian rangelelands. Appl. Anim. Behav. Sci. 2010, 126, 75-84. [CrossRef]

(C) 2019 by the authors. Licensee MDPI, Basel, Switzerland. This article is an open access article distributed under the terms and conditions of the Creative Commons Attribution (CC BY) license (http://creativecommons.org/licenses/by/4.0/). 